Published in final edited form as:

J Hosp Palliat Nurs. 2012 ; 14(1): 61-70. doi:10.1097/NJH.0b013e318236de5c.

\title{
The Symptom Experience of Patients with Cancer
}

\author{
Laurie Stark, PhD, RN, \\ Instructor, University of South Florida, College of Nursing, 12901 Bruce B. Downs Blvd., Tampa, \\ FL 33612, 813-974-1938 \\ Cindy Tofthagen, PhD, ARNP, \\ Assistant Professor, University of South Florida, College of Nursing \\ Constance Visovsky, PhD, ARNP, and \\ Associate Dean and Associate Professor, University of South Florida, College of Nursing \\ Susan C. McMillan, PhD, ARNP, FAAN \\ Distinguished University Health Professor, University of South Florida, College of Nursing And \\ Center for Hospice, Palliative Care and End of Life Studies
}

Laurie Stark: Lstark1@health.usf.edu

\section{Introduction}

There is little doubt that despite advances in supportive cancer care, unrelieved symptoms continue to be both prevalent and persistent in the cancer patient population whether in cancer centers or hospices. ${ }^{1}$ The symptom experience of cancer patients remains an important area for nursing research and practice. The symptom experience consists of the perception and response to symptom occurrence and related symptom distress. ${ }^{2}$ Persistent, unrelieved symptoms impair quality of life (QOL) including activities of daily living, engagement in social and emotional well being and relationships. ${ }^{3}$ Symptom severity and symptom distress are aspects of the symptom experience that require assessment in order to fully understand the symptom experience. In some cases, symptom severity and symptom distress may not correlate with each other, and thus, the most severe symptoms may not present as the most distressing. ${ }^{4}$ Careful symptom assessment that includes severity and distress are critical aspects of quality palliative care.

\section{Review of Literature}

Symptoms as a result of cancer disease and treatment are both pervasive and persistent despite cancer type, disease stage or treatment received. ${ }^{1,5}$ Symptoms such as pain and fatigue represent two of the most common symptoms present in individuals undergoing cancer treatment. ${ }^{6,7}$ Fatigue remains among the most commonly reported and distressing symptom experienced by persons with cancer, as it interferes with the individual's ability to perform daily activities. 5

Prevalent and/or persistent symptoms cause distress by interference with activities of daily living and their ability to impair quality of life. ${ }^{8}$ Despite advances in pain management, pain remains a common persistent symptom among persons with cancer. Estimates of pain prevalence among persons with cancer range from $14 \%-100 \% .{ }^{1}$ In a population-based study, vanden Beuken-van Everdingen et al. concluded that pain control remains inadequate in $42 \%$ of patients, especially among those receiving curative cancer therapies. ${ }^{9}$ Given et al. found pain was most likely to occur within 40 days of receiving surgery, chemotherapy or radiation. ${ }^{10}$ Patients presenting with pain tend to have more advanced disease and thus, more other symptoms. 
Symptom severity and symptom distress represent unique aspects of quality of life. However, despite the advent of clinical guidelines, symptom experiences often remain difficult to characterize due to a relative lack of gold-standard assessments and few evidence-based interventions. Cancer-related pain is an example of a symptom perceived as having aspects that encompass both severity and distress and for which national clinical guidelines exist. ${ }^{11}$ However, as noted above, despite clinical guidelines for addressing cancer-related pain, it remains poorly controlled. ${ }^{9}$ In 2004, the National Institutes of Health issued a State of the Science Conference Statement concerning cancer-related pain, depression and fatigue that addressed the need for routine brief assessments of these symptoms, and implementation of evidence-based interventions. ${ }^{1}$

Symptom distress is defined as physical or mental upset, anguish or suffering reported as a result of specific symptoms. ${ }^{2}$ In one study of cancer patients receiving home health-based hospice care, the lack of energy, dry mouth, pain, shortness of breath, feeling bloated and difficulty sleeping were the most distressing problems reported. ${ }^{4}$ Furthermore, symptom distress was noted to be an important predictor of quality of life. In a cross-sectional, observational study of 180 patients with hematologic malignancies, the most distressing symptoms were difficulty sleeping, pain, constipation, difficulty swallowing, problems with urination, low libido, swelling in the extremities and hair loss. These symptoms were reported as causing quite a bit to very much distress in 40-50\% of patients. Patients with refractory disease reported the highest number of symptoms (mean $=8.8)$ and highest levels of physical distress. ${ }^{12}$ It is important to note that while symptom distress and symptom severity may be related they are not the same. There may be differing patterns of symptom prevalence, intensity and distress depending on the trajectory of the individual's illness. Due to the relatively high prevalence and persistence of multiple symptoms across the cancer continuum of care, routine, systematic assessment of symptom presence, severity and distress is needed. ${ }^{12}$

The purpose of this secondary analysis was to describe the symptom experience of patients with cancer. Specifically, we report:

1. Mean number of symptoms reported and which symptoms are most commonly occurring

2. Mean severity of symptoms and symptoms that have that highest severity

3. Mean distress of symptoms and symptoms that cause the most distress

\section{Methods}

\section{Setting}

H. Lee Moffitt Cancer Center \& Research Institute is an NCI-designated comprehensive cancer center that sees more than 7,000 new patients annually with a variety of cancers. The outpatient clinics have approximately 220,000 patient visits annually, and the inpatient area has 205 beds. The Infusion Center has more than 40,000 patient visits annually, and radiation therapy department had 43,413 visits in 2010. Study participants were drawn from all outpatient clinics and the Infusion Center.

\section{Sample}

A sample of 393 patients with cancer was available in the database of a larger on-going NIH-funded study designed to evaluate an intervention for medication-induced constipation in persons with cancer. To be included, patients had to be receiving daily opioids for treatment of pain, receiving vinca alkaloids for treatment of their cancer, or be receiving 
both opioids and vinca alkaloids. Dose of medication was not an inclusion criterion. A total of 298 patients reporting pain were used in this analysis.

Patients with any type of cancer except a primary colorectal or gynecologic cancer, with any stage of disease, were included. Those on opioids were on stable doses for two days before the beginning of the study. Patients receiving vinca alklaloids had to have at least two scheduled doses of the vinca alkaloid medication remaining at the time of accrual. They had to be adults over 18 years, and able to consent, be alert, and able to read and understand English. Only persons who reported pain were included in this analysis.

Patients were excluded if they were excessively debilitated or deemed unlikely to survive for the eight weeks of the data collection period; if they were unable to read and understand English; if they had an ostomy that changed bowel function; if they had a current peritoneal catheter; if they had had abdominal surgery within the past six weeks; if they were currently having radiation therapy to the abdomen; if they had a history of chronic bowel disease (including irritable bowel syndrome, chronic constipation prior to cancer onset, Crohn's disease, ulcerative colitis or diarrhea as a result of radiation to the pelvis), a disease process suggestive of mechanical obstruction (tumor or adhesion), or reported chronic laxative use prior to cancer onset. Patients were excluded from the study if they appeared to have an impaction at the time baseline data were collected.

\section{Instruments}

\section{Short Portable Mental Status Questionnaire}

Because the data were self reported by patients, the 10-item Short Portable Mental Status Questionnaire (SPMSQ) was used as a screening instrument for cognitive impairment. While the SPMSQ is a brief instrument that may lack sensitivity to mild cognitive impairment, it has demonstrated validity in detecting moderate to severe cognitive impairment. ${ }^{13}$

\section{Memorial Symptom Assessment Scale (MSAS)}

2.Memorial Symptom Assessment Scale (MSAS) was used to help investigators better understand the full array of symptoms experienced by this group of patients and to help to better describe them. Several researchers have called for differentiating symptom distress from symptom intensity and frequency. ${ }^{2,14,15,16}$ One expert defined symptom distress as "how bothered" the patients were by the symptom. ${ }^{14}$ The MSAS was designed to differentiate among occurrence, intensity, and distress from symptoms and has 33 items reflecting symptoms commonly associated with cancer in 3 dimensions: (1) severity of the symptom; (2) frequency with which it occurs; and (3) the distress it produces. In the parent study, frequency (on a scale of $1=$ rarely experienced to $4=$ almost constantly experienced) data was not collected; therefore, it was not included in our analysis. In addition, since our primary goal was to examine which symptoms were the most severe and which caused the most distress, we did not conduct subscale analysis.

Validity and reliability_-Validity and reliability data for the MSAS have been strong when the tool was used with persons receiving active cancer therapy. ${ }^{17}$ Factor analysis confirmed two factors that distinguished three major groups of symptoms. The three confirmed groups of symptoms were Psychological, High Prevalence and Low Prevalence Physical Symptoms. 


\section{Demographic Data}

Standard demographic data was collected on patients to allow description of the sample. Data included: age; gender; education level; marital status; religious affiliation, type of cancer and stage of cancer.

\section{Procedures}

After approval was received from the Scientific Review Committee of the Cancer Center, the proposal was submitted to the Institutional Review Board for the University of South Florida. Data collection began after written approval was received.

Accrual

Patients in the outpatient clinics were screened using the computerized data system and patients who met study criteria were invited to participate in the study. The study was explained and questions answered by the research assistants. If the patient agreed and signed the consent, patients were screened with the SPMSQ to insure that they were able to selfreport. Baseline data were collected during that regular outpatient visit.

\section{Data Analysis}

Demographic data were analyzed using descriptive statistics. The research aims were analyzed using means, standard deviations, frequencies and percentages. Only patients who endorsed a given symptom (such as fatigue or shortness of breath) were included in the analysis of that specific symptom.

\section{Results \\ Sample}

The sample consisted of 298 participants who were primarily white, non-Hispanic, married, Catholic or non-Catholic Christians, currently receiving some type of cancer treatment with either palliative or curative intent. More females than males were included in this sample (Table 1). Participants had a variety of solid tumors and hematologic malignancies, although the majority of the sample had breast cancer, lung cancer, or lymphoma (Table 2). Only 64 patients were receiving vinca alkaloids; the rest were admitted to the parent study because they were receiving opioids. Ages ranged from 21-84 with a mean of 54.2 years ( $\mathrm{SD}=11.9)$.

\section{Symptom Occurrence}

Patients reported between 2 and 30 symptoms each with a mean of 14.1 (SD=5.5). Having pain was an inclusion criterion, so it was the most frequently reported symptom ( $\mathrm{n}=298$, $100 \%)$. Among the other symptoms, the most frequently endorsed symptoms were lack of energy/fatigue $(\mathrm{n}=272,91.3 \%)$, feeling drowsy $(\mathrm{n}=199,66.8 \%)$, difficulty with sleeping $(\mathrm{n}=196,65.8 \%)$ and worrying $(\mathrm{n}=193,64.8 \%)($ Table 3$)$.

\section{Symptom Severity}

Hair loss and problems with sexual activity or interest were the most severe symptoms $(m e a n=2.6)$. To aid in interpretation of these means, since nurses are accustomed to using a $0-10$ scale for symptom severity, we converted them from a 0 to 4 scale to a 0 to 10 scale. The most severe symptoms listed thus had scores of 6.5 . These were followed by pain, lack of energy/fatigue and "I don't look like myself" with means of 2.5, or 6.25 on the 0 to 10 scale (Table 4). Problems with sexual activity or interest and hair loss were reported to be severe or very severe by at least $50 \%$ of participants who reported the symptom. Conversely, 
diarrhea, cough, and dizziness were severe or very severe in less than $20 \%$ of participants who reported the symptom (Table 5).

\section{Symptom Distress}

Again, for the distress scores, we converted this 0 to 4 scale to a 0 to 10 scale and added those numbers to the table. Lack of energy/fatigue was reported by patients to be the most distressing symptom (mean $=2.8$, or 7.0). This was followed by pain, difficulty sleeping (means both=2.7 or 6.8), worrying and constipation (means 2.5 or 6.3) (Table 6). Pain, difficulty sleeping, lack of energy/fatigue and "I don't look like myself" were reported to be "quite a bit" or "very distressing" by at least 50\% of participants reporting the symptom. Weight loss, itching, and cough were reported as "quite a bit" or "very distressing" by less than $30 \%$ of participants reporting the symptom (Table 7).

\section{Discussion}

\section{Sample}

A strength of the study was the large sample size with patients having a variety of cancer diagnoses. As in earlier studies, the symptoms with the greatest severity were not necessarily the same as those that were the most distressing. For example, hair loss was reported to be severe or very severe by $52.5 \%$ of participants while being rated 4.3 on a scale of $0-10$. There is a potential for distress among cancer patients beyond those symptoms related to pain and chemotherapy treatments. Individuals from a cultural minority represent less than $15 \%$ of the total participants in this study. While this percentage is typical of the population treated at tertiary cancer care centers, symptom distress among those from diverse cultures remains unclear. The majority of participants enrolled in this study are women; this is consistent with the tendency of more women than men to participate in research. ${ }^{18} \mathrm{~A}$ limitation of this study is that the study participants come from a larger sample with inclusion criteria that restricted enrollment to only those who were receiving opiods, vinca alkyloids, or both. An additional limitation of this study is that $70 \%$ of the participants had more advanced disease.

\section{Symptom Occurrence}

A large number of symptoms occurring concurrently were reported by patients (Table 3 ). It should be noted that while pain was the most common symptom reported at $100 \%$, this doubtless occurred because patients were accrued to a study of opioid-induced constipation. In earlier symptom studies of cancer patients, fatigue was the most commonly seen in more than $91 \%$ of the patients; this is consistent with earlier studies. ${ }^{19,20}$

The next most frequently reported symptom was feeling drowsy. This result might have occurred due to the use of opioids, but the literature suggests that this is equally likely to be due to daytime napping. ${ }^{21}$ Constipation was reported by $62 \%$ if the sample. This probably occurred because some clinicians are attending to the problem and others are not.

\section{Symptom Severity}

Symptoms with the greatest severity for this group of cancer patients were hair loss and impaired sexual activity; however, these problems were not the most distressing problems (Table 6). The Look Good-Feel Better program sponsored by the American Cancer Society provides a network for cancer patients that include information and access to support for a symptom such as hair loss. ${ }^{22}$ However, in order for patients to know about and benefit from this program the nurse must make a referral; it is not known how often this type of referral is made. 
Other high intensity symptoms included fatigue, pain and lack of appetite among the symptoms that were most distressing. There are evidence-based interventions for these problems; all could be better managed than they seem to have been for this group of patients.

\section{Symptom Distress}

The participants in this study reported significant symptom distress. With $100 \%$ of the patients reporting distress from pain and $91.3 \%$ with distress from lack of energy, worrying and constipation also were noted as distressing. The experience of continuous symptom distress has been shown to deplete the positive attitude that is essential to combating anxiety and depression among cancer patients. ${ }^{23}$ While nurses often focus on symptom severity, there is still less of a focus on ameliorating symptom distress.

\section{Conclusions}

Despite prevalent and persistent energy and research spent on identifying and treating the distress patients experience from cancer-related symptoms, the problem persists. Generally, nurses are knowledgeable and skilled at evaluating symptom severity in cancer patients. In addition to having awareness and being knowledgeable about the symptoms that cause the most distress for cancer patients, nurses must also be aware of and knowledgeable about the resources that offer support to their patients. In addition to asking about the presence of symptoms patients may be experiencing, nurses must also inquire about the associated distress. Through the use of a $0-10$ distress scale, in addition to the intensity ratings commonly used to assess symptom severity, nurses can assess the symptoms that are causing the most distress for their patients. This practice will assist nurses in prioritizing their care and providing the much needed support and education for this population. Assessing symptom distress experienced by the hospice or palliative care patient presents an opportunity for the nurse to develop a plan of care that is addresses the unique needs of the individual.

These important issues should be the focus of on-going research as well as nursing education both in service areas and in schools of nursing. Research is needed to develop and test interventions so that clinicians can implement evidence based interventions to improve symptom distress for their patients.

\section{Acknowledgments}

The support of the National Institute for Nursing Research is gratefully acknowledged (R01 NR 010751)

\section{References}

1. Patrick D, Ferketich S, Frame P, et al. National Institutes of Health state of the science conference statement: Symptom management in cancer: Pain, depression and fatigue. J Natl Cancer Inst Monogr. 2004; 32:9-16. July 15-17, 2002. [PubMed: 15263035]

2. Rhodes VA, McDaniel RW, Matthews CA. Hospice patients and nurses perceptions of self-care deficits based on symptom experience. Cancer Nursing. 1998; 21:312-319. [PubMed: 9775481]

3. McMillan SC, Weitzner MA. Quality of life in cancer patients: Use of a revised hospice index. Cancer Practice. 1998; 6:282-288. [PubMed: 9767348]

4. McMillan SC, Small BJ. Symptom distress and quality of life in patients with cancer newly admitted to hospice home care. Oncology Nursing Forum. 2002; 29(10):1421-1428. [PubMed: 12432413] 
5. Lawrence DP, Kupelnick B, Miller K, Devine D, Lau J. Evidence report on the occurrence, assessment, and treatment of fatigue in cancer patients. J Natl Cancer Inst Monogr. 2004; 32:40-50. [PubMed: 15263040]

6. Luctkar-Flude M, Groll D, Tranmer J, Woodend K. Fatigue and physical activity in older adults with cancer: A systematic review of the literature. Cancer Nursing. 2007; 30:E35-E45. [PubMed: 17876176]

7. Laird BJA, Scott AC, Colvin LA, McKeon AL, Murray GD, Fearon KCH, Fallon MT. Pain, depression and fatigue as a symptom cluster in advanced cancer. J Pain \& Symptom Management. 2011 Mar 12.:1-11. E-Pub.

8. Beck S, Dudley W, Barsevick A. Pain, sleep disturbance and fatigue in patients with cancer: Using a mediation model to test a symptom cluster. Oncology Nursing Forum. 2005; 32(3):E48-E55.

9. vanden Beuken-van Everdingen MHJ, de Rijke JM, Kesselss AG, Schouten HC, van Kleef M, Patijn J. High prevalence of pain in patients with cancer in a large population-based study in The Netherlands. Pain. 2007; 132:312-320. [PubMed: 17916403]

10. Given C, Given B, Azzouz F, Kozachik S, Strommel M. Predictors of pain and fatigue in the year following diagnosis among elderly cancer patients. J Pain Symptom Management. 2001; 21:456466.

11. Benedetti, et al. NCCN Practice Guidelines for Cancer Pain. Oncology. 2007; 14(11A):135-150. [PubMed: 11195407]

12. Manitta V, Zordan R, Cole-Sinclair M, Nandurkar H, Philip J. The symptom burden of patients with hematological malignancy: A cross-sectional observational study. J Pain \& Symptom Management. 2011 in press.

13. MacNeill, SE.; Lichtenberg, PA. Screening instruments and brief batteries for assessment of dementia. In: Lichtenberg, PA., editor. Handbook of assessment in clinical gerontology. New York: John Wiley; 1999. p. 417-441.

14. Chiou CP. Development and psychometric assessment of the Physical Symptom Distress Scale. J Pain Symptom Management. 1998; 16(2):87-95.

15. McClement S, Woodgate R, Degner L. Symptom distress in adult patients with cancer. Cancer Nursing. 1997; 20(4):236-43. [PubMed: 9265809]

16. Tishelman C, Degner L. Measuring symptom distress in patients with lung cancer. Cancer Nursing. 2000; 23(2):83-90.

17. Portenoy RK, Thaler HT, Kornblith AB, et al. The Memorial Symptom Assessment Scale: An instrument for the evaluation of symptom prevalence, characteristics and distress. European Journal of Cancer. 1994; 30A(9):1326-1336. [PubMed: 7999421]

18. McMillan SC, Small BJ, Weitzner M, Schonwetter R, Tittle M, Moody L, Haley WE. Impact of Coping Skills Intervention with Family Caregivers of Hospice Patients with Cancer: A Randomized Clinical Trial. Cancer. 2006; 106(1):214-222. [PubMed: 16329131]

19. Prue G, Allen J, Gracey J, Rankin J, Cramp F. Fatigue in gynecological cancer patients during and after anticancer therapy. J Pain Symptom Management. 2010; 39(2):197-210.

20. Scott JA, Lasch KE, Barsevick AM, Piault-Louis E. Patient's experiences with cancer-related fatigue: A review and synthesis of qualitative research. Oncology Nursing Forum. 2011; 38(3):E191-E203. [PubMed: 21531669]

21. McChargue DE, Sankaranarayanan J, Visovsky CG, Matthews EE, Highland KB, Berger AM. Predictors of adherence to a behavioral therapy sleep intervention during breast cancer chemotherapy. Supportive Care Cancer. 2010 Online First, Dec. 2010.

22. American Cancer Society. [Accessed June 15, 2011] Look Good...Feel Better Find Support and Treatment. http://www.cancer.org/Treatment/SupportProgramsServices/look-good-feel-better

23. Hou WK, Law CC, Fu YT. Does change in positive affect mediate and/or moderate the impact of symptom distress in psychological adjustment after cancer diagnosis? A prospective analysis. Psychology \&Health. 2010; 25(41):417-431. [PubMed: 20397294] 
Table 1

Frequency and Percent of Patients by Gender, Ethnicity, Marital status, Religious Affiliation, Stage of Cancer, and Stage of Treatment

\begin{tabular}{|c|c|c|}
\hline Demographic Variable & Frequency & Percent \\
\hline Gender: Female & 172 & 57.7 \\
\hline Male & 125 & 41.9 \\
\hline Missing & 1 & $<1$ \\
\hline \multicolumn{3}{|l|}{ Ethnicity } \\
\hline White, non-Hispanic & 254 & 85.2 \\
\hline Black, non-Hispanic & 21 & 7.0 \\
\hline White, Hispanic & 19 & 6.4 \\
\hline Black, Hispanic & 1 & $<1$ \\
\hline Asian-Pacific Islander & 1 & $<1$ \\
\hline Other & 1 & $<1$ \\
\hline Missing & 1 & $<1$ \\
\hline \multicolumn{3}{|l|}{ Marital Status } \\
\hline Married & 184 & 61.7 \\
\hline Single & 57 & 19.1 \\
\hline Divorced & 43 & 14.4 \\
\hline Widowed & 14 & 4.7 \\
\hline \multicolumn{3}{|l|}{ Religious Affiliation } \\
\hline Non-Catholic Christian & 162 & 54.4 \\
\hline Catholic & 68 & 22.8 \\
\hline None & 43 & 14.4 \\
\hline Other & 19 & 6.4 \\
\hline Jewish & 5 & 1.7 \\
\hline \multicolumn{3}{|l|}{ Stage of Disease } \\
\hline I & 17 & 5.7 \\
\hline II & 23 & 7.7 \\
\hline III & 49 & 16.4 \\
\hline IV & 104 & 34.9 \\
\hline Missing data & 105 & 35.2 \\
\hline \multicolumn{3}{|l|}{ Stage of Treatment } \\
\hline Newly diagnosed, not in treatment & 1 & $<1$ \\
\hline Curative treatment & 89 & 29.6 \\
\hline Palliative treatment ${ }^{a}$ & 104 & 34.9 \\
\hline Symptom management only & 10 & 3.4 \\
\hline In remission; pain management only & & \\
\hline
\end{tabular}


Table 2

\section{Frequency and Percent of Patients by Primary Cancer}

\begin{tabular}{lcc} 
Type of Cancer & Frequency & Percent \\
\hline Breast & 56 & 18.8 \\
Lung & 55 & 18.5 \\
Lymphoma & 49 & 16.4 \\
Leukemia & 28 & 9.4 \\
Multiple Myeloma & 17 & 5.7 \\
Melanoma & 15 & 5.0 \\
Non-melanoma skin cancer (Basal/Squamous cell) ${ }^{a}$ & 12 & 4.0 \\
Pancreatic & 10 & 3.4 \\
Head and Neck & 9 & 3.0 \\
Prostate & 8 & 2.7 \\
Gastrointestinal & 5 & 1.7 \\
Other solid tumors & 25 & 8.4 \\
Missing & 1 & $<1$ \\
\hline These were all deeply invasive skin cancers that had metastasized &
\end{tabular}


Table 3

\section{Frequency and Percent of Patients reporting Each Symptom on the MSAS}

\begin{tabular}{|c|c|c|}
\hline Symptom & Frequency & Percent \\
\hline Pain & 298 & 100 \\
\hline Lack of energy/fatigue & 272 & 91.3 \\
\hline Feeling drowsy & 199 & 66.8 \\
\hline Difficulty Sleeping & 196 & 65.8 \\
\hline Worrying & 193 & 64.8 \\
\hline Constipation & 185 & 62.1 \\
\hline Numbness/tingling in hands or feet & 167 & 56.0 \\
\hline Feeling sad & 163 & 54.7 \\
\hline Dry Mouth & 161 & 54.0 \\
\hline Feeling irritable & 160 & 53.7 \\
\hline Change in taste & 156 & 52.3 \\
\hline Difficulty Concentrating & 151 & 50.7 \\
\hline Lack of appetite & 151 & 50.7 \\
\hline "I don't look like myself" & 146 & 49.0 \\
\hline Nausea & 133 & 44.6 \\
\hline Hair loss & 130 & 43.6 \\
\hline Feeling bloated & 129 & 43.3 \\
\hline Shortness of breath & 128 & 43.0 \\
\hline Feeling Nervous & 127 & 42.6 \\
\hline Dizziness & 112 & 37.6 \\
\hline Problem with sexual activity or interest & 99 & 33.2 \\
\hline Weight loss & 94 & 31.5 \\
\hline Cough & 92 & 30.9 \\
\hline Swelling of arms and legs & 92 & 30.9 \\
\hline Itching & 82 & 27.5 \\
\hline Difficulty swallowing & 71 & 23.8 \\
\hline Nightmares & 64 & 21.5 \\
\hline Vomiting & 63 & 21.1 \\
\hline Problems with urination & 58 & 19.5 \\
\hline Mouth sores & 49 & 16.4 \\
\hline Urinary accidents & 44 & 14.8 \\
\hline Diarrhea & 34 & 11.4 \\
\hline
\end{tabular}


Table 4

Mean, Standard Deviation and Converted Score for Severity of Each Symptom

\begin{tabular}{|c|c|c|c|c|}
\hline \multirow[b]{2}{*}{ Symptom } & \multirow[b]{2}{*}{$\mathbf{n}$} & \multicolumn{2}{|c|}{ Severity } & \multirow{2}{*}{$\begin{array}{c}\text { Converted Score } \\
0-10\end{array}$} \\
\hline & & Mean & SD & \\
\hline Hair loss & 130 & 2.6 & 1.3 & 6.5 \\
\hline Problem with sexual activity or interest & 99 & 2.6 & 1.2 & 6.5 \\
\hline Pain & 298 & 2.5 & 1.1 & 6.3 \\
\hline Lack of energy/fatigue & 272 & 2.5 & 1.0 & 6.3 \\
\hline "I don't look like myself" & 146 & 2.5 & 1.2 & 6.3 \\
\hline Difficulty Sleeping & 196 & 2.4 & 1.1 & 6.0 \\
\hline Worrying & 193 & 2.4 & 1.1 & 6.0 \\
\hline Constipation & 185 & 2.4 & 1.1 & 6.0 \\
\hline Problems with urination & 58 & 2.4 & 1.1 & 6.0 \\
\hline Numbness/tingling in hands or feet & 167 & 2.3 & 1.1 & 5.8 \\
\hline Nightmares & 64 & 2.3 & 1.3 & 5.8 \\
\hline Swelling of arms and legs & 92 & 2.2 & 1.1 & 5.5 \\
\hline Change in taste & 156 & 2.2 & 1.1 & 5.5 \\
\hline Lack of appetite & 151 & 2.1 & 1.1 & 5.3 \\
\hline Feeling bloated & 129 & 2.1 & 1.0 & 5.3 \\
\hline Dry Mouth & 161 & 2.1 & 1.1 & 5.3 \\
\hline Feeling irritable & 160 & 2.0 & 1.0 & 5.0 \\
\hline Feeling Nervous & 127 & 2.0 & 1.0 & 5.0 \\
\hline Difficulty swallowing & 71 & 2.0 & 1.1 & 5.0 \\
\hline Mouth sores & 49 & 2.0 & 1.1 & 5.0 \\
\hline Nausea & 133 & 2.0 & 1.0 & 5.0 \\
\hline Feeling drowsy & 199 & 2.0 & 1.0 & 5.0 \\
\hline Feeling sad & 163 & 1.9 & 1.1 & 4.8 \\
\hline Shortness of breath & 128 & 1.9 & 1.1 & 4.8 \\
\hline Weight loss & 94 & 1.9 & 1.1 & 4.8 \\
\hline Itching & 82 & 1.9 & 1.1 & 4.8 \\
\hline Vomiting & 63 & 1.9 & 1.1 & 4.8 \\
\hline Dizziness & 112 & 1.8 & 0.9 & 4.5 \\
\hline Urinary accidents & 44 & 1.8 & 1.1 & 4.5 \\
\hline Difficulty Concentrating & 151 & 1.7 & 1.5 & 4.3 \\
\hline Cough & 92 & 1.6 & 0.9 & 4.0 \\
\hline Diarrhea & 34 & 1.6 & 1.1 & 4.0 \\
\hline
\end{tabular}

J Hosp Palliat Nurs. Author manuscript; available in PMC 2013 January 01. 
Table 5

Frequency and percent of participants reporting each symptom as severe or very severe.

\begin{tabular}{|c|c|c|c|}
\hline Symptom & $\mathbf{n}$ & Frequency & severe or very severe \\
\hline Problem with sexual activity or interest & 99 & 52 & 52.5 \\
\hline Hair loss & 130 & 68 & 52.3 \\
\hline Pain & 298 & 147 & 49.3 \\
\hline Lack of energy/fatigue & 270 & 33 & 49.2 \\
\hline "I don't look like myself" & 146 & 71 & 48.6 \\
\hline Constipation & 185 & 79 & 43.7 \\
\hline Difficulty Sleeping & 194 & 85 & 43.4 \\
\hline Nightmares & 64 & 27 & 42.2 \\
\hline Worrying & 193 & 81 & 42.0 \\
\hline Numbness/tingling in hands or feet & 166 & 68 & 41.0 \\
\hline Swelling of arms and legs & 92 & 37 & 40.2 \\
\hline Problems with urination & 58 & 23 & 39.7 \\
\hline Change in taste & 156 & 58 & 37.2 \\
\hline Dry Mouth & 161 & 57 & 35.4 \\
\hline Lack of appetite & 151 & 51 & 33.8 \\
\hline Mouth sores & 49 & 16 & 32.7 \\
\hline Feeling bloated & 129 & 41 & 31.8 \\
\hline Feeling drowsy & 199 & 63 & 31.7 \\
\hline Difficulty swallowing & 71 & 22 & 31.0 \\
\hline Nausea & 132 & 40 & 30.3 \\
\hline Feeling irritable & 159 & 44 & 27.7 \\
\hline Feeling nervous & 127 & 35 & 27.6 \\
\hline Vomiting & 62 & 17 & 27.4 \\
\hline Itching & 82 & 22 & 26.8 \\
\hline Urinary accidents & 44 & 11 & 25.0 \\
\hline Feeling sad & 163 & 40 & 24.5 \\
\hline Shortness of breath & 128 & 30 & 23.4 \\
\hline Weight loss & 94 & 22 & 23.4 \\
\hline Dizziness & 112 & 21 & 18.8 \\
\hline Difficulty Concentrating & 151 & 28 & 18.6 \\
\hline Diarrhea & 34 & 6 & 17.7 \\
\hline Cough & 92 & 16 & 17.4 \\
\hline
\end{tabular}


Table 6

Mean, Standard Deviation and Converted Score for Distress of Each Symptom

\begin{tabular}{|c|c|c|c|c|}
\hline \multirow[t]{2}{*}{ Symptom } & \multirow[b]{2}{*}{$\mathbf{n}$} & \multicolumn{2}{|c|}{ Distress } & \multirow{2}{*}{$\begin{array}{c}\text { Converted Score } \\
\text { 0-10 }\end{array}$} \\
\hline & & Mean & SD & \\
\hline Lack of energy/fatigue & 272 & 2.8 & 1.1 & 7.0 \\
\hline Pain & 298 & 2.7 & 1.2 & 6.8 \\
\hline Difficulty Sleeping & 196 & 2.7 & 1.2 & 6.8 \\
\hline Constipation & 185 & 2.5 & 1.3 & 6.3 \\
\hline Worrying & 193 & 2.5 & 1.2 & 6.3 \\
\hline Problems with urination & 58 & 2.4 & 1.3 & 6.0 \\
\hline Problem with sexual activity or interest & 99 & 2.4 & 1.5 & 6.0 \\
\hline Swelling of arms and legs & 92 & 2.4 & 1.3 & 6.0 \\
\hline "I don't look like myself" & 146 & 2.4 & 1.4 & 6.0 \\
\hline Numbness/tingling in hands or feet & 167 & 2.3 & 1.3 & 5.8 \\
\hline Nausea & 133 & 2.3 & 1.3 & 5.8 \\
\hline Feeling Nervous & 127 & 2.3 & 1.3 & 5.8 \\
\hline Nightmares & 64 & 2.3 & 1.4 & 5.8 \\
\hline Mouth sores & 49 & 2.3 & 1.3 & 5.8 \\
\hline Urinary accidents & 44 & 2.3 & 1.4 & 5.8 \\
\hline Feeling sad & 163 & 2.2 & 1.2 & 5.5 \\
\hline Vomiting & 63 & 2.2 & 1.4 & 5.5 \\
\hline Shortness of breath & 128 & 2.2 & 1.2 & 5.5 \\
\hline Feeling bloated & 129 & 2.2 & 1.2 & 5.5 \\
\hline Feeling irritable & 160 & 2.1 & 1.3 & 5.3 \\
\hline Change in taste & 156 & 2.1 & 1.3 & 5.3 \\
\hline Difficulty Concentrating & 151 & 2.1 & 1.4 & 5.3 \\
\hline Difficulty swallowing & 71 & 2.0 & 1.2 & 5.0 \\
\hline Lack of appetite & 151 & 1.9 & 1.3 & 4.8 \\
\hline Dry Mouth & 161 & 1.9 & 1.3 & 4.8 \\
\hline Itching & 82 & 1.9 & 1.2 & 4.8 \\
\hline Dizziness & 112 & 1.9 & 1.2 & 4.8 \\
\hline Feeling drowsy & 199 & 1.9 & 1.3 & 4.8 \\
\hline Hair loss & 130 & 1.7 & 1.5 & 4.3 \\
\hline Cough & 92 & 1.6 & 1.2 & 4.0 \\
\hline Diarrhea & 34 & 1.6 & 1.3 & 4.0 \\
\hline Weight loss & 94 & 1.4 & 1.4 & 3.5 \\
\hline
\end{tabular}




\section{Table 7}

Frequency and percent of participants reporting each symptom as quite a bit or very bothersome.

\begin{tabular}{|c|c|c|c|}
\hline Symptom & $\mathbf{n}$ & Frequency & Percent \\
\hline Pain & 296 & 174 & 58.8 \\
\hline Difficulty Sleeping & 194 & 110 & 56.7 \\
\hline Lack of energy/fatigue & 269 & 168 & 56.3 \\
\hline "I don't look like myself" & 144 & 72 & 50.0 \\
\hline Constipation & 184 & 90 & 48.9 \\
\hline Problem with sexual activity or interest & 99 & 48 & 48.5 \\
\hline Feeling nervous & 126 & 60 & 47.6 \\
\hline Mouth sores & 49 & 23 & 46.9 \\
\hline Urinary accidents & 43 & 20 & 46.5 \\
\hline Worrying & 192 & 89 & 46.4 \\
\hline Swelling of arms and legs & 92 & 42 & 45.7 \\
\hline Nightmares & 64 & 29 & 45.3 \\
\hline Numbness/tingling in hands or feet & 166 & 73 & 44.2 \\
\hline Problems with urination & 57 & 25 & 43.9 \\
\hline Feeling bloated & 128 & 56 & 43.8 \\
\hline Nausea & 130 & 54 & 41.5 \\
\hline Vomiting & 62 & 26 & 41.9 \\
\hline Difficulty Concentrating & 149 & 59 & 39.6 \\
\hline Change in taste & 155 & 59 & 38.1 \\
\hline Lack of appetite & 150 & 55 & 36.7 \\
\hline Shortness of breath & 128 & 47 & 36.7 \\
\hline Difficulty swallowing & 70 & 25 & 35.7 \\
\hline Feeling drowsy & 197 & 69 & 35.0 \\
\hline Feeling irritable & 159 & 55 & 34.6 \\
\hline Hair loss & 128 & 42 & 32.8 \\
\hline Dry Mouth & 161 & 52 & 32.3 \\
\hline Dizziness & 111 & 35 & 31.5 \\
\hline Feeling sad & 163 & 61 & 31.4 \\
\hline Itching & 82 & 21 & 25.6 \\
\hline Cough & 92 & 22 & 23.9 \\
\hline Diarrhea & 34 & 8 & 23.5 \\
\hline Weight loss & 94 & 22 & 23.4 \\
\hline
\end{tabular}

